Original Research Article

\title{
Effect of fixed dose combinations of different $\alpha 1$-blockers with dutasteride on quality of life in patients of lower urinary tract symptoms with benign prostatic hyperplasia
}

\author{
Nishant Madan ${ }^{1}$, M. C. Gupta ${ }^{1 *}$, Hemant Kamal ${ }^{2}$
}

${ }^{1}$ Department of Pharmacology,

${ }^{2}$ Department of Urology, Pt. BD Sharma PGIMS, Rohtak,

Haryana, India

Received: 11 April 2019

Accepted: 07 May 2019

*Correspondence to:

Dr. M. C. Gupta,

Email:

dr.mcgupta57@gmail.com

Copyright: (C) the author(s), publisher and licensee Medip Academy. This is an openaccess article distributed under the terms of the Creative Commons Attribution NonCommercial License, which permits unrestricted noncommercial use, distribution, and reproduction in any medium, provided the original work is properly cited.

\begin{abstract}
Background: Fixed dose combination (FDC's) of $\alpha 1$-blockers and $5 \alpha$-reductase inhibitors have commonly been used in patients with lower urinary tract symptoms (LUTS) and benign prostatic hyperplasia (BPH). This study compared the effect of FDC's of tamsulosin, alfuzosin and silodosin with dutasteride on quality of life (QoL) in patients of LUTS with BPH.

Methods: Ninety-six male patients aged $\geq 45$ years diagnosed with LUTS and $\mathrm{BPH}$ were randomized to receive FDC's of dutasteride with tamsulosin (group 1), alfuzosin (group 2) and silodosin (group 3) over a period of 16 weeks. Quality of life was assessed using International Prostate Symptom Score (IPSS) $8^{\text {th }}$ question, BPH impact index (BII) and modified Patient Perception of Study Medication (PPSM) questionnaire.

Results: IPSS $8^{\text {th }}$ question score improved significantly by $61.68 \%, 57.63 \%$ and $63.4 \%$ in group 1, 2 and 3 respectively. BPH Impact Index score also improved significantly by $62.95 \%, 60.13 \%$ and $61.82 \%$ in group 1,2 and 3 respectively. All the three treatments were found to be similar in improving the QoL. Majority of patients were satisfied with their treatment and wanted to receive the medication again while a small number of patients were neutral with the study medication. None of the subjects was dissatisfied with any of the treatment.

Conclusions: All the FDC's improved QoL and were found to be satisfactory as per patient perception of study medications.
\end{abstract}

Keywords: Benign prostatic hyperplasia, Dutasteride, Fixed dose combinations, Lower urinary tract symptoms, Quality of life, $\alpha 1$-blockers

\section{INTRODUCTION}

Benign prostatic hyperplasia (BPH) is a non-malignant enlargement of the prostate gland. The enlarged prostate may compress the urethra and result in anatomic bladder outlet obstruction (BOO) which may present as lower urinary tract symptoms (LUTS), infections, retention and other adverse events. ${ }^{1}$
Lower urinary tract symptoms (LUTS) are a group of disorders comprising of obstructive and irritative symptoms. Obstructive symptoms or voiding LUTS, includes hesitancy, weak and interrupted stream of urine, straining to initiate urination, dribbling of urine and a sense of incomplete bladder emptying. Irritative symptoms or storage LUTS, typically occur late in the disease course and include urinary frequency, urgency and nocturia. ${ }^{2}$ 
LUTS with BPH are not often a life-threatening condition but they are associated with diminished health-related quality-of-life (QoL) as well as increased healthcare expenditures. In the Boston Area Community Health (BACH) Survey it was seen that LUTS were common among both men and women and increased substantially with age and had a negative impact on quality of life. Increased severity of LUTS was associated with greater limitations of daily activities and significant decrements in physical and mental well-being in every age, sex and race/ethnicity category. ${ }^{3}$

In a cross-sectional analysis from a cohort study, 5284 men aged 65 years or more without a history of prostate cancer were recruited from six US clinical centres and it was found that moderate-to severe LUTS and dissatisfaction with their current urinary status were common and strongly associated with poorer health status and physical impairment. Also, men with more severe LUTS had greater urinary symptom bother and consistently lower perceptions of general health status than did men with more moderate LUTS. ${ }^{4}$

Association of prostatic enlargement and heath related quality of life (HRQoL) was studied by Girman et al, and its was found that men with enlarged prostates were nearly 3 times as likely to have moderate to severe symptoms and about twice as likely to have bother or activity interference relative to men with smaller prostates. ${ }^{5}$

LUTS may also be associated with serious non-urological morbidity like increased risk of fall as shown in a study by Parson et al. The association of LUTS with risk of falls in elderly community-dwelling man was evaluated and it was found that in the first year after assessing LUTS, men with moderate or severe LUTS were at greater risk of falls than those with mild LUTS and the symptoms most strongly associated with falls were urgency, straining, and nocturia. $^{6}$

The impact of LUTS with BPH on quality of life can be significant and should not be underestimated. The effect of BPH-associated LUTS on QoL is the most important motivation for seeking treatment. Improvement in LUTS tends to improve quality of life. In a study by Sountoulides et al, both voiding and storage symptoms correlated with QoL with the latter exhibiting slightly tighter correlations. The association was found not only at baseline but also after treatment. ${ }^{7}$

The treatment for LUTS with BPH comprises of both medical and surgical. For medical management, $\alpha$ adrenergic blockers and $5 \alpha$-reductase inhibitors (5-ARIs) are commonly used. $\alpha$-adrenergic blockers improve symptoms by rapidly reducing smooth muscle tone in the prostate and bladder neck but have no effect on prostate enlargement and therefore do not affect the disease progression. 5-ARIs target the underlying pathology of $\mathrm{BPH}$ by inhibiting the production of DHT and by reducing prostate volume, treat LUTS and attenuate disease progression. However, it takes a few months before clinical improvement is apparent. Patients with large prostate (volume $>30 \mathrm{~cm}^{3}$ ) obtain greater relief than those with smaller gland.${ }^{8,9}$ Combined administration of a steroid $5 \alpha$-reductase inhibitor and $\alpha 1$-adrenergic antagonists can rapidly improve urinary symptoms and thus quality of life.

The present study was conducted to assess and compare the effect of fixed dose combinations of dutasteride with three different $\alpha 1$-blockers on quality of life and treatment satisfaction in patients of moderate to severe LUTS with $\mathrm{BPH}$.

\section{METHODS}

It was a prospective, open label, randomized, comparative, pilot clinical study conducted by the Department of Pharmacology and Urology, Pt. BD Sharma PGIMS, Rohtak, Haryana, India between March 2017 and March 2018.

Patient's inclusion criteria were age $\geq 45$ years of age and diagnosed to have LUTS and BPH, International Prostate Symptom Score (IPSS) $\geq 8$, prostate volume $\geq 30 \mathrm{~cm}^{3}$, total serum prostate specific antigen (PSA) $\leq 10 \mathrm{ng} / \mathrm{ml}$, two urinary voids at screening with maximum urinary flow rate $\left(\mathrm{Q}_{\max }\right) \geq 5 \mathrm{ml} / \mathrm{sec}$ and $\leq 15 \mathrm{ml} / \mathrm{sec}$ with a minimum voided volume $\geq 125 \mathrm{ml}$ and patients who were ready to give written informed consent. Patients with history or evidence of prostate cancer, previous prostate surgery, history of acute urinary retention (AUR) within 3 months of the screening visit were excluded. Also patients who had received $\alpha$-blocker within 2 weeks or 5-ARIs within 6 months of screening visit, patients with a history of intolerance or hypersensitivity to the study drugs, patients who had serious concomitant illness which could prevent the completion of study, any co-morbidities which are likely to confound the study and who did not agree for the informed consent were not included.

Study was done in accordance with the principles of Good Clinical Practice (ICH-GCP) and Declaration of Helsinki. An informed consent was obtained from all patients enrolled for the study. The study was approved by Institutional Review Board (IRB).

\section{Study treatment and assessment}

An adequate number of patients were screened and selected as per the inclusion and exclusion criteria for the study. A total of 104 patients who fulfilled the criteria were randomized assigned into one of the three treatment groups according to a computer-generated randomization schedule at study entry, and treated either with FDC of tamsulosin $0.4 \mathrm{mg}$ and dutasteride $0.5 \mathrm{mg}$ once daily (group 1), FDC of alfuzosin $10.0 \mathrm{mg}$ and dutasteride 0.5 $\mathrm{mg}$ once daily (group 2) or FDC of silodosin $4.0 \mathrm{mg}$ and dutasteride $0.5 \mathrm{mg}$ once daily (Group 3). Patients were followed-up every 4 weeks for a period of 16 weeks. In each group 32 patients completed the study for 16 weeks. 
The quality of life is assessed by IPSS $8^{\text {th }}$ question and BPH impact index, which were evaluated at baseline and at end of 16 weeks and modified PPSM questionnaire which was evaluated at study end. ${ }^{10-12}$ In IPSS $8^{\text {th }}$ question, patient is asked if he had to spend the rest of his life with his urinary condition just the way it is now, how would he feel about that and scaled from 0 (delighted) to 6 (terrible). $\mathrm{BPH}$ impact index is a 4-item patient completed questionnaire that measures the impact of BPH symptoms on physical symptoms, worry about health, degree of bother, and limitations of daily activities, with a higher score indicating a worse health impact of BPH symptoms. Possible score can range from 0 (no impact) to 13 (highest negative impact). PPSM was evaluated by a modified and validated method. The responses to questions pertaining to satisfaction with study medication i.e. question 2, 4, 10 and 11 were included in the study excluding questions related to improvement by study medication and questions related to pain. Without these questions, the psychometric performance of the PPSM was maintained. In addition to this, intent to ask for study medication again (item 12) was also included for analysis.
Data was tabulated in Microsoft Excel Sheet. Data was expressed as Mean \pm SEM, number (\%) depending on nature of data. Data was subjected to descriptive statistical analysis. The results of IPSS $8^{\text {th }}$ question and BPH Impact Index were compiled and analysed using paired " $t$ " test and one-way ANOVA test as appropriate. The response to modified PPSM was expressed as percentage. All the statistical analysis was performed using SPSS version 23.0 software. $\mathrm{P}$ value $<0.05$ was considered significant.

\section{RESULTS}

Of the 104 patients randomized to treatment, $96(92.3 \%)$ completed the week 16 visit with comparable rates of discontinuation in the 3 treatment groups. Table 1 lists patient demographics and baseline characteristics. They were comparable in all the treatment groups.

- Impact of treatment on quality of life (QoL).

- International prostate symptom score (IPSS $8^{\text {th }}$ question).

Table 1: Baseline characteristics of study population.

\begin{tabular}{|llll|}
\hline Variables & $\begin{array}{l}\text { Group 1 }(\mathbf{n = 3 2}) \\
\text { Mean } \pm \text { SEM }\end{array}$ & $\begin{array}{l}\text { Group 2 }(\mathbf{n = 3 2}) \\
\text { Mean } \pm \text { SEM }\end{array}$ & $\begin{array}{l}\text { Group 3 }(\mathrm{n}=32) \\
\text { Mean } \pm \text { SEM }\end{array}$ \\
\hline Age (years) & $65.28 \pm 1.60$ & $66.53 \pm 1.36$ & $66.66 \pm 1.32$ \\
\hline Body weight $(\mathrm{kg})$ & $73.81 \pm 1.16$ & $73.28 \pm 1.43$ & $75.5 \pm 1.15$ \\
\hline Duration $($ months $)$ & $8.91 \pm 1.33$ & $9.88 \pm 1.21$ & $8.56 \pm 0.76$ \\
\hline Prostate volume $\left(\mathrm{cm}^{3}\right)$ & $40.38 \pm 1.16$ & $39.44 \pm 1.00$ & $39.34 \pm 1.00$ \\
\hline PSA $(\mathrm{ng} / \mathrm{ml})$ & $2.6 \pm 0.16$ & $2.81 \pm 0.15$ & $2.47 \pm 0.14$ \\
\hline IPSS & $17.88 \pm 0.54$ & $17.5 \pm 0.49$ & $17.75 \pm 0.53$ \\
\hline Qmax $(\mathrm{ml} / \mathrm{sec})$ & $10.57 \pm 0.47$ & $10.11 \pm 0.44$ & $10.08 \pm 0.35$ \\
\hline Total voided volume $(\mathrm{ml})$ & $236.93 \pm 10.04$ & $245.9 \pm 9.3$ & $243.88 \pm 9.38$ \\
\hline
\end{tabular}

All values are expressed as Mean \pm SEM, Group 1: FDC of Tamsulosin $0.4 \mathrm{mg}$ and Dutasteride $0.5 \mathrm{mg}$ once daily, Group 2: FDC of Alfuzosin $10 \mathrm{mg}$ and Dutasteride $0.5 \mathrm{mg}$ once daily, Group 3: FDC of Silodosin $4 \mathrm{mg}$ and Dutasteride $0.5 \mathrm{mg}$ once daily.

In group 1 , baseline score of $4.41 \pm 0.25$ significantly reduced to $1.69 \pm 0.24$ ( $\mathrm{p}<0.001$ ). In group 2 , statistically significant reduction was seen at 16 weeks as compared to baseline score of $4.13 \pm 0.21$. The score reduced to $1.75 \pm 0.27$ ( $p<0.001)$. The same was observed in group 3 where the baseline score of $4.29 \pm 0.23$ significantly reduced to $1.57 \pm 0.24(\mathrm{p}<0.001)$.

There was a significant reduction in IPSS $8^{\text {th }}$ question score in all the 3 groups which is indicating that all the drugs were effective in reducing the score and hence improving the quality of life in LUTS and BPH patients. There was no statistically significant difference in improvement of QoL amongst the groups and the results were equivocal in all the groups (Figure 1).

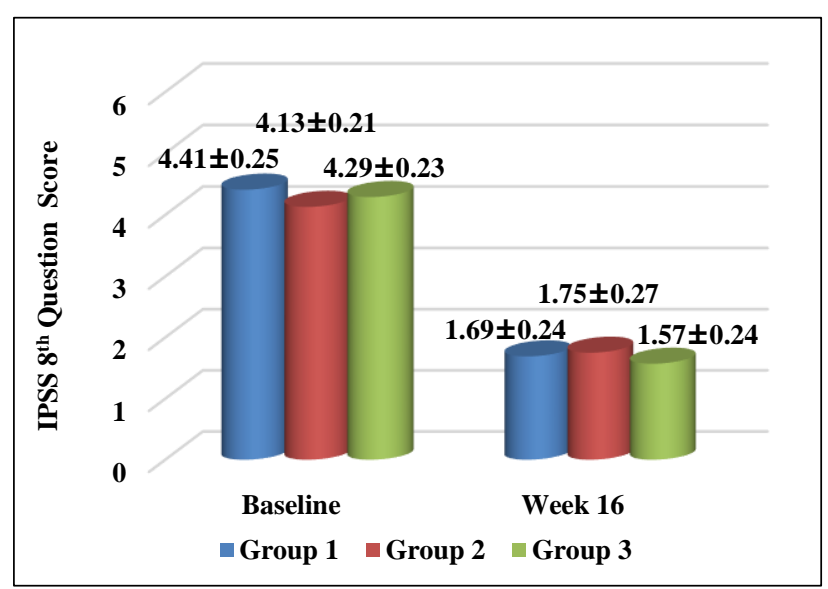

Figure 1: Comparison of changes in quality of life (IPSS Question $8^{\text {th }}$ ). 


\section{BPH Impact Index (BII)}

In group 1, baseline score for BPH impact index was $6.91 \pm 0.52$ which reduced to $2.56 \pm 0.51$ ( $\mathrm{p}<0.001)$. This reduction was statistically significant. In group 2, statistically significant reduction was seen and score of $5.97 \pm 0.47$ reduced to $2.38 \pm 0.5$ ( $p<0.001)$. The same was observed in group 3 where the baseline score of $6.47 \pm 0.57$ reduced significantly to $2.47 \pm 0.48$ ( $\mathrm{p}<0.001$ ). There was no statistically significant difference in improvement of QoL between the groups and all the groups were equally effective. There was a significant reduction in $\mathrm{BPH}$ impact index score at week 16 in all the 3 groups indicating that all the FDC's were effective in reducing the score and improving the quality of life in LUTS with BPH patients (Figure 2).

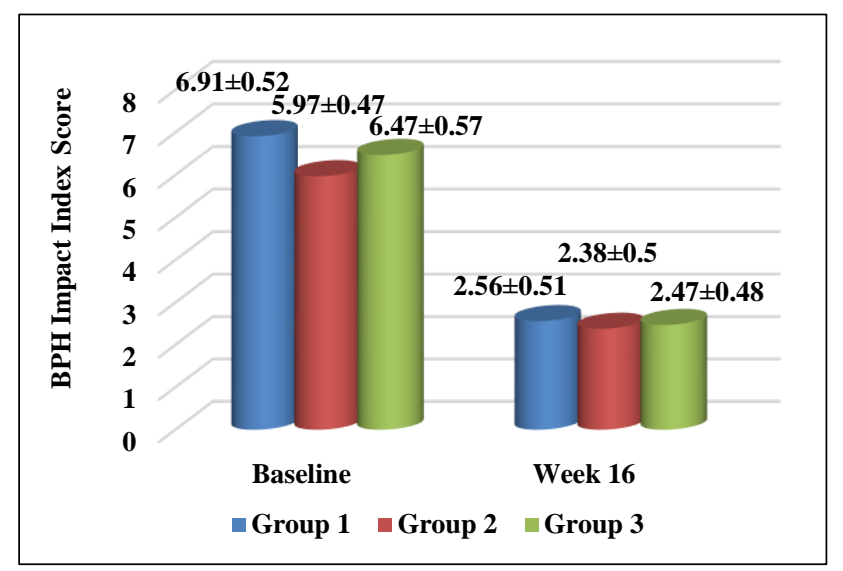

Figure 2: Comparison of changes in quality of life (BPH Impact Index).

\section{Patient's Perception of Study Medication (PPSM)}

The study considered only questions 2, 4, 10, 11 and 12 . With regard to question 2, which refers to satisfaction with the study medication on control of urinary problem, 29 patients in group 1, 28 in group 2 and 29 in group 3 were satisfied with the study medication. Rest of the patients were neutral and none of the patients was dissatisfied.

Question 4 pertains to satisfaction of study medication on the strength of the urinary system, 29 patients in group 1, 28 in group 2 and 29 in group 3 were satisfied with the study medication and rest of the patients were neutral and none was dissatisfied.

With regards to question 10 , which refers to satisfaction with study medication on interference with ability to go about usual activities due to urinary problems, 29, 28 and 29 patients in group 1, 2 and 3 respectively were satisfied with the study medication. Rest of the patients were neutral. None of the patients was dissatisfied.

Question 11 which about overall satisfaction of a patient with the study medication and its effect on his urinary problems 29 patients in group 1 is 28 in Group 2 and 29 in group 3 were satisfied with the study medications and rest were neutral. None of the patients was dissatisfied with the study drugs.

The observations are indicative that in large number of patients, there was satisfaction with the study medication while very small number of patients were neutral with the study medication (Table 2).

Table 2: Response to PPSM questions in three groups.

\begin{tabular}{|c|c|c|c|c|c|c|}
\hline Study groups & Group 1 & & Group 2 & & Group 3 & \\
\hline PPSM Questions & Satisfied & $\begin{array}{l}\text { Neutral/Not } \\
\text { satisfied }\end{array}$ & Satisfied & $\begin{array}{l}\text { Neutral/Not } \\
\text { satisfied }\end{array}$ & Satisfied & $\begin{array}{l}\text { Neutral/Not } \\
\text { satisfied }\end{array}$ \\
\hline $\begin{array}{l}\text { Q2. Satisfaction on control of urinary } \\
\text { problem. }\end{array}$ & 29 & 3 & 28 & 4 & 29 & 3 \\
\hline $\begin{array}{l}\text { Q4. Satisfaction on the strength of the } \\
\text { urinary system. }\end{array}$ & 29 & 3 & 28 & 4 & 29 & 3 \\
\hline $\begin{array}{l}\text { Q10. Satisfaction on interference with } \\
\text { ability to go about usual activities due } \\
\text { to urinary problems. }\end{array}$ & 29 & 3 & 28 & 4 & 29 & 3 \\
\hline $\begin{array}{l}\text { Q11. Overall satisfaction with the } \\
\text { study medication and its effect on his } \\
\text { urinary problems. }\end{array}$ & 29 & 3 & 28 & 4 & 29 & 3 \\
\hline
\end{tabular}

With regards to question 12, will the patient ask the doctor for study medication, 23 patients in group 1, 21 in group 2 and 23 in group 3 responded yes i.e. they wanted to receive and continue with the study medication. Three patients in group 1, 4 in group 2 and 3 in group 3 said no i.e. they did not want to receive the study medication. Six patients in group 1, 7 in group 2 and 6 in Group 3 were not sure (Figure 3). Majority of the patients in the 3 groups wanted to receive the study medication which is indicative of the 
fact that majority of patients had improved symptoms and were satisfied with the study medication.
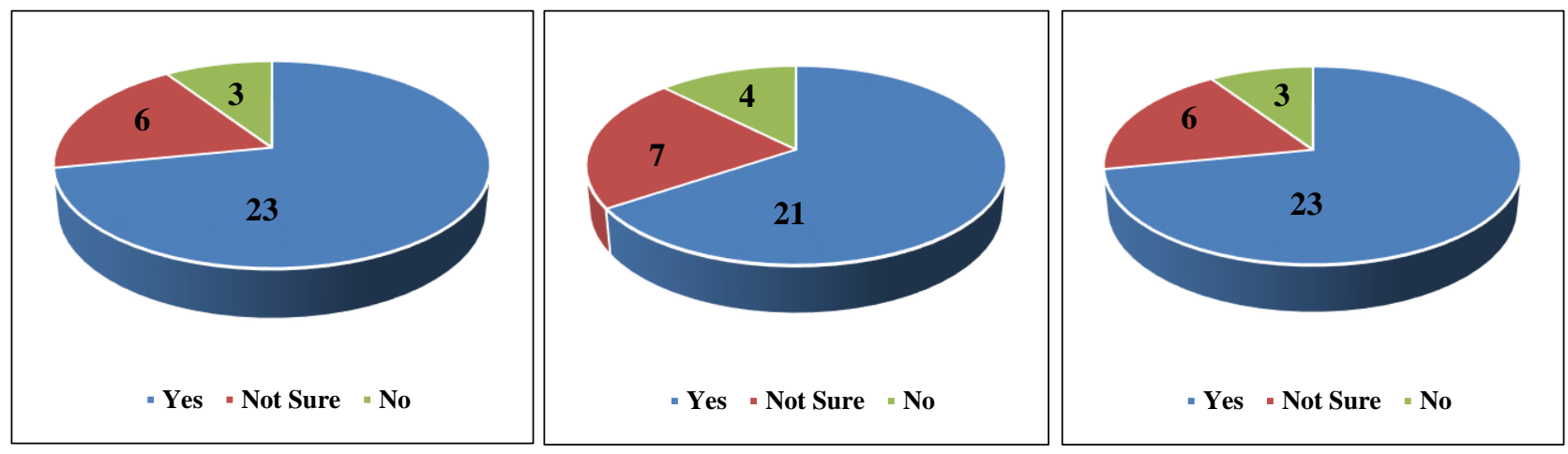

Figure 3: Response to PPSM Questionnaire (Question 12). A) Group 1, B) Group 2, C) Group 3.

\section{DISCUSSION}

In the present study, all the three groups showed a comparable and statistically significant improvement in response to IPSS $8^{\text {th }}$ question and $\mathrm{BPH}$ impact index on quality of life. This QoL improvement can be ascribed to relief in lower urinary tract symptoms in BPH. All threestudy treatment were FDC's of $\alpha$-adrenergic blockers and 5ARI and it is now widely known that $\alpha$-adrenergic blockers relax the smooth muscle tissue in the prostate and bladder neck and provides a relatively rapid improvement of LUTS while 5ARIs acts gradually by reducing the prostate volume. Both drugs act synergistically to improve LUTS in BPH and hence an improvement in quality of life. The findings of the study match with the pharmacological profile of combination therapy.

In pre-planned analysis of CombAT trial, the decrease in response to IPSS $8^{\text {th }}$ question with combination therapy of tamsulosin and dutasteride at 3 months was 1.0 point as compared to baseline which was statistically significant in comparison to dutasteride monotherapy ( 0.6 points, $p$ $<0.001$ ) but comparable to decrease in tamsulosin monotherapy group (0.9 points) ${ }^{13}$ The decrease in combination group was statistically significant as compared to baseline IPSS $8^{\text {th }}$ question score. BPH impact index score also decrease significantly at 3 months with combination therapy. A reduction of 1.5 point was seen as compared to baseline score of $5.3 \pm 3.04$. In the conduct study, the decrease in response to IPSS $8^{\text {th }}$ question at 3 months with combination of tamsulosin and dutasteride was around 1.0 point as compared to baseline (3.2 \pm 1.15$)$ which was statistically significant. For BPH Impact Index, the decrease in response to BII at 3 months with combination therapy was 1.5 point as compared to baseline $(5.3 \pm 3.04)$ which was statistically significant. ${ }^{14}$ The findings of the present study are quite similar to these studies with reference to the FDC used in these studies. The reduction in score of both IPSS 8th question and BPH impact index with three FDCs was statistically significant ye comparable at 16 weeks.

On assessment of PPSM, larger number of patients showed satisfaction with the study medication while very small number of patients were neutral or dissatisfied with the study medication in all the study groups. Also, majority of the patients in the 3 groups wanted to receive the study medication which is indicative of the fact that majority of patients had either improved symptoms or were satisfied with the study medication. In pre-planned analysis of CombAT trial, question 1-4 and 9-12 were asked from the patients. ${ }^{13}$ A total of $76 \%$ patients had positive response i.e. they had improvement in symptoms, were satisfied with the study medication and wanted to receive the same medication. In another post hoc analysis of the CombAT trial, a total of 107 Asian patients who received combination of tamsulosin and dutasteride were assessed for response at 24 months. ${ }^{15}$ For each of the 12 questions in the PPSM questionnaire, higher percentage of patients responded positively. On the overall satisfaction score (item 11), 91\% of patients reported satisfaction. The findings of present study are quite similar to the abovementioned studies as large number of patients were satisfied with the study medication and had improved symptoms after receiving the treatment with combination therapy of tamsulosin and dutasteride. The findings indicate that majority of patients taking FDCs of either tamsulosin, alfuzosin and silodosin with dutasteride were satisfied with the treatment and wanted to continue with the same medication.

\section{CONCLUSION}

Fixed dose combinations of dutasteride, a 5ARI, with three $\alpha$-adrenergic antagonists, tamsulosin, alfuzosin and silodosin, caused a significant and comparable improvement in quality of life in LUTS with BPH patients. Similarly, all the three FDCs were equally effective with respect to satisfaction with the study medications. The 
observation indicates that any of the FDCs can be used with respect to quality of life and medication satisfaction.

\section{ACKNOWLEDGEMENTS}

Authors would like to thank patients for their support during study.

Funding: No funding sources

Conflict of interest: None declared

Ethical approval: The study was approved by the Institutional Review Board

\section{REFERENCES}

1. Stroup SP, Palazzi-Churas K, Kopp RP, Parsons JK. Trends in adverse events of benign prostatic hyperplasia (BPH) in the USA, 1998 to 2008. BJU Int 2012;109:84-7.

2. Scher HI, Eastham JA. Benign and Malignant Diseases of the Prostate. In: Kasper DL, Fausi AS, Hauser SL, Longo DL, Jameson JL, Loscalzo J, editors. Harrison's Principles of Internal Medicine. 19th ed. New York: McGraw-Hill; 2015: 579-87.

3. Kupelian V, Wei JT, O’Leary MP, Kusek JW, Litman HJ, Link CL, et al. Prevalence of lower urinary tract symptoms and effect on quality of life in a racially and ethnically diverse random sample. The Boston Area Community Health (BACH) Survey. Arch Intern Med. 2006;166:2381-7.

4. Taylor BC, Wilt TJ, Fink HA, Lambert LC, Marshall LM, Hoffman AR, et al. Prevalence, severity, and health correlates of lower urinary tract symptoms among older men: The MrOS study. Urol. 2006;68:804-9.

5. Girman CJ, Jacobsen SJ, Rhodes T, Guess HA, Roberts RO, Lieber MM. Association of health-related quality of life and benign prostatic enlargement. Eur Urol. 1999;35:277-84.

6. Parsons JK, Mougey J, Lambert L, Wilt TJ, Fink HA, Garzotto M, et al. Lower urinary tract symptoms increase the risk of falls in older men. BJU Int. 2009; 104:63-8.

7. Sountoulides P, Dijk MM, Wijkstra H, Rosette JJ, Michel MC. Role of voiding and storage symptoms for the quality of life before and after treatment in men with voiding dysfunction. World J Urol. 2010;28:3-8.

8. Rosenberg MT, Witt ES, Miner M, Barkin J. A practical primary care approach to lower urinary tract symptoms caused by benign prostate hyperplasia (BPH-LUTS). Can J Urol. 2014;21(2):12-24.
9. Boyle P, Roehrborn C, Harkaway R, Logie J, de la Rosette J, Emberton M. 5-Alpha reductase inhibition provides superior benefits to alpha blockade by preventing AUR and BPH-related surgery. Eur Urol. 2004;45:620-6.

10. Badia X, Garcia-Losa M, Dal-Re R. Ten-language translation and harmonisation of the international prostate symptom score: developing a methodology for multinational clinical trials. Eur Urol. 1997;31:129-40.

11. Kingery L, Martin ML, Naegeli AN, Khan S, Viktrup L. Content validity of the Benign Prostatic Hyperplasia Impact Index (BII); a measure of how urinary trouble and problems associated with $\mathrm{BPH}$ may impact the patient. Int $\mathbf{J}$ Clin Pract. 2012;66(9):883-90.

12. Black L, Grove A, Morrill B. The psychometric validation of a US English satisfaction measure for patients with benign prostatic hyperplasia and lower urinary tract symptoms. Health Qual Life Outcomes. 2009;7:55.

13. Barkin J, Roehrborn CG, Siami P, Haillot O, Morrill B, Black L, et al. Effect of dutasteride, tamsulosin and the combination on patient-reported quality of life and treatment satisfaction in men with moderate-to-severe benign prostatic hyperplasia: 2-year data from the CombAT trial. BJU Int. 2009;103:919-26.

14. Roehrborn CG, Perez IO, Roos EPM, Calomfirescu N, Brotherton B, Wang F, et al. Efficacy and safety of a fixed-dose combination of dutasteride and tamsulosin treatment (Duodart $\AA$ ) compared with watchful waiting with initiation of tamsulosin therapy if symptoms do not improve, both provided with lifestyle advice, in the management of treatment-naïve men with moderately symptomatic benign prostatic hyperplasia: 2-year Conduct study results. BJU Int. 2015;116:450-9.

15. Chung BH, Roehrborn CG, Siami P, Major-Walker K, Morrill BB, Wilson TH, et al. Efficacy and safety of dutasteride, tamsulosin and their combination in a subpopulation of the CombAT study: 2-year results in Asian men with moderate-to-severe BPH. Prostate Cancer Prostatic Dis. 2009;12:152-9.

Cite this article as: Madan N, Gupta MC, Kamal H. Effect of fixed dose combinations of different $\alpha 1$ blockers with dutasteride on quality of life in patients of lower urinary tract symptoms with benign prostatic hyperplasia. Int J Basic Clin Pharmacol 2019;8:1248-53. 